\title{
The application of motion controller in the control system of plate shearing machine
}

\author{
Gui-Zhi ZHAO 1,a , Da-Peng LIU ${ }^{2, b}$ \\ ${ }^{1}$ Inner Mongolia University for the Nationalities, College of Mechanical Engineering, Tong Liao, \\ 028000, China. \\ ${ }^{2}$ NO.724 Research Institute under CSIC, Nanjing Jiangsu 210003, China; \\ aguizhi_84@yahoo.com.cn, 'liudapeng@163.com,
}

Keywords: Plate shearing machine, Motion controller, Control system.

\begin{abstract}
Plate shearing machine is widely used in industrial automation system, there are some shortcomings of the traditional control system of plate shearing machine, such as low accuracy, poor reliability etc. In view of this situation, in this paper, a kind of plate shearing machine is designed based on motion controller, plate shearing machine is analyzed, the design of the hardware and software is done. Experiments show that, the system has high precision, good reliability, it can complete the plate shearing process automation, it has a certain practical significance.
\end{abstract}

\section{Introduction}

The system of the position automatic control is a control method, it has universal application of more application, for example, in the CNC machine, material conveying system and the length of the plate detection system [1]. With the continuous development of industrial automation, automatic position control system has been in the application of plate shearing machine, it can replace manual labor shears, reduce labor costs, and improve production efficiency [2]. The traditional plate shearing machine adopts relay and contactor control, relay and contactor system hardware wiring is complex, system aging speed is accelerated, once a fault occurs, it is difficult to check, the system reliability is poor, it will affect the efficiency of the system [3]. There are some plate shearing machines are controlled by PLC, there are some problems in the control precision using PLC [4]. In recent years, the motion controller with high control precision, fast response and so on has been widely used [5]. In order to overcome the shortcomings of traditional plate shearing machine control system, $t$ in this paper, a kind of plate shearing machine is designed based on motion controller, it can effectively solve the problems existing in the traditional plate shearing machine, it has a certain practical significance.

\section{Hardware design}

Overall design. As shown in Figure 1, plate shearing machine mainly consists of several parts of a feeding mechanism, a clamping mechanism, a shearing mechanism and storage mechanism. The four part are driven by four servo motors, the storage mechanism is a car, after shearing a number of plate, the car will send them to designated locations. The working process of plate shearing machine is: system detects whether plate receiving position is empty, if empty, and the material storage car did not reach the required number, feeding mechanism starts to move, the plate moves forward by the friction between the driving roller, when the plate trigger the clamping switch, it stops motion, clamping mechanism moves, it will do plate compaction, shear mechanism starts to do plate shearing. After shearing, the plate falls into the material storage car, when it reaches a certain number, the plate will be sent to the specified position by car. After returning, the next cycle starts. 


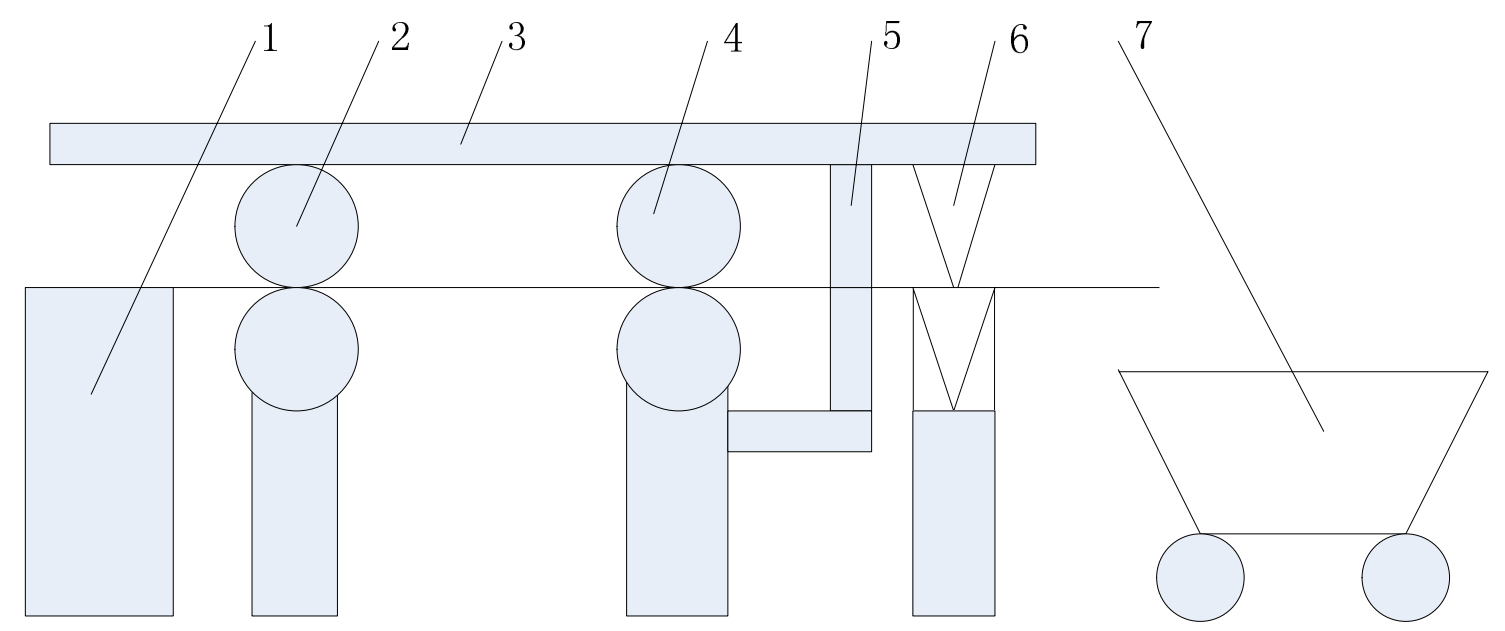

1. Feeding mechanism 2. Driving roller 3.Frame 4.Measuring roller 5.Clamping mechanism

6.Shearing mechanism 7.Storage mechanism

Figure 1.The plate shearing machine schematic diagram

Control system design. Shearing machine control system in this paper is designed based on motion controller, motion controller is the core of the control system, it controls the coordinated motion between the various mechanisms, detects the plate shearing machine state information, and ensures the safe and stable operation of shearing machine. It controls the mechanism of coordination according to the feedback signal, and completes shearing process through the coordination of movement mechanism. The motion controller cannot run independently, it needs PC as the host machine of the motion controller, do programming and debugging of the motion controller. The sensor is used to detect the running state of the shearing machine. The servo system provides the driving force for the various mechanism, it receives the motion controller motion commands, and drives coordinated motion of various mechanism. The motion controller and other hardware integration are shown in figure 2.

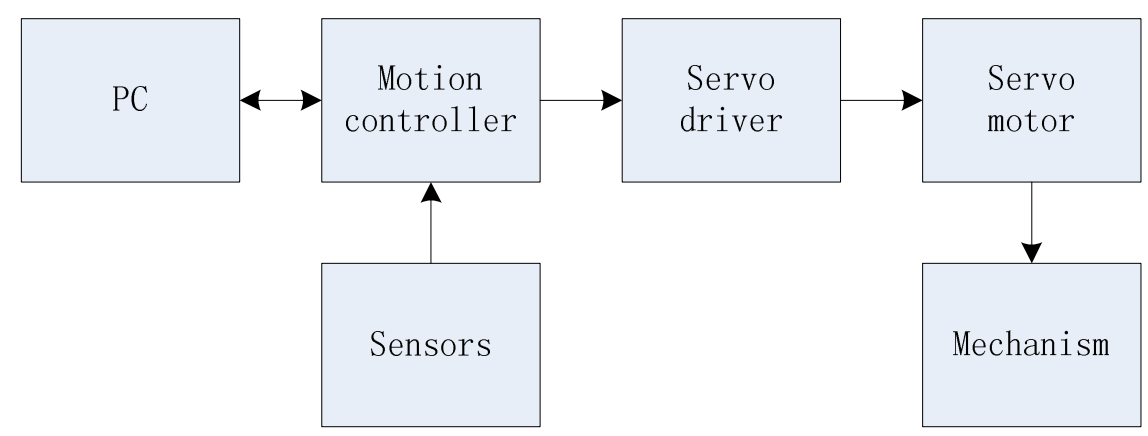

Figure 2.The hardware integration

\section{Software design}

Software structure design. The motion controller is a kind of open controller based on PC, it cannot work independently, it only has operating environment, not program development, program development is completed by PC. As shown in Figure 3, the software design takes the way of the upper and lower computer, program development is mainly completed by upper computer, including the overall program planning and management, they are completed in the PC machine; motion controller is lower computer, it used to perform the written motion control program. The communication between the upper and lower machine through Ethernet, it can be directly debugging. After debugging, it can be directly transmitted to the motion controller, this program can be run independently from the upper computer in motion controller. 


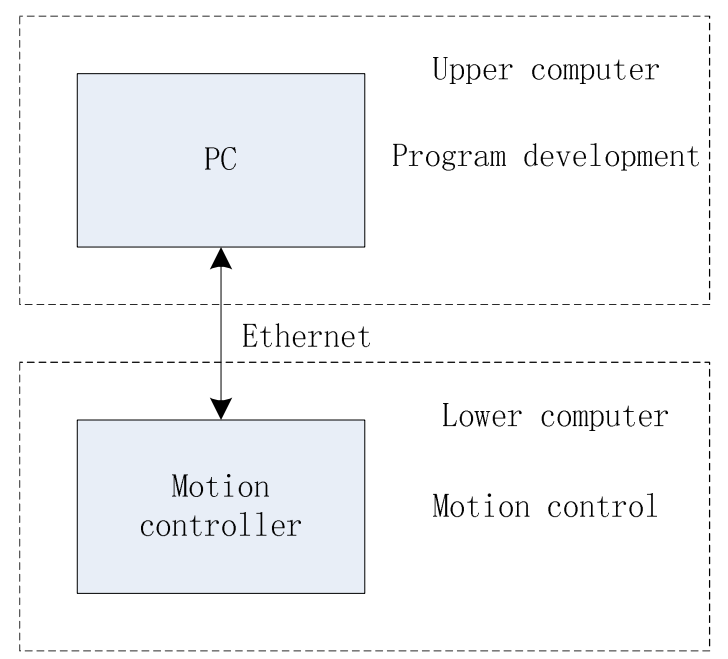

Figure3. Software structure

Program flow design. According to the control requirements of plate shearing machine, program flow of control system is shown in figure 4. The program initialization is done before the work, testing the state of the shearing machine, if there is no fault, shearing machine is ready to start work. Select the operating mode of the system, it is divided into automatic mode and manual mode. After selecting the system will detect the material storage car and receiving opening position information, if it is ready, system controls feeding mechanism to work. Feed mechanism drives the wheel to drive plate to move forward, the system will detect the plate position, when reaching the clamping position, plate stops motion, clamping mechanism will clamp plate, and shear it, after shearing, it falls into the material storage car, then the next cycle start. The system will automatically detect any fault, if the failure will stop running, the initialization program and automatically return.

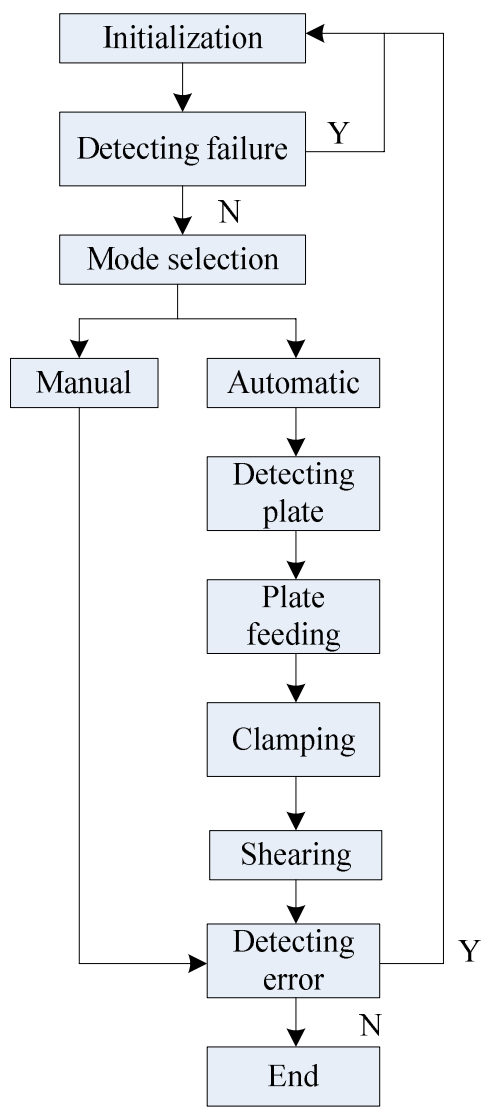

Figure4. Work flow 
I/O design. The system needs to detect the external signal, and send signal. Signal transmitting and receiving are completed through the $\mathrm{I} / \mathrm{O}$ interface controller, the system design of $\mathrm{I} / \mathrm{O}$ is shown in table 1.

Table1. System I/O design

\begin{tabular}{c|c|c|c}
\hline \multicolumn{2}{c|}{ Input } & \multicolumn{2}{c}{ Output } \\
\hline IN0 & $\begin{array}{c}\text { The material } \\
\text { storage } \\
\text { photoelectric } \\
\text { switch }\end{array}$ & OUT0 & Indicator light 1 \\
\hline IN1 & $\begin{array}{c}\text { Airborne } \\
\text { switch }\end{array}$ & OUT1 & Indicator light 2 \\
\hline IN2 & $\begin{array}{c}\text { Clamping } \\
\text { photoelectric } \\
\text { switch }\end{array}$ & OUT2 & Indicator light 3 \\
\hline & & OUT3 & Indicator light 4 \\
\hline
\end{tabular}

\section{Summary}

In this paper, in view of the traditional defects of shearing machine system, a kind of shearing machine is designed based on the motion controller, shearing machine can realize the whole process automation of feeding, clamping, shearing, transportation. Using the motion controller can improve the system flexibility and scalability. The system has good reliability, low maintenance costs, it can reduce maintenance and maintenance time, and improve the level of automation equipment. The shear experiment is carried, the result proves that the system is feasible, it and can improve processing efficiency and reduce production cost. It has a certain practical value.

\section{References}

[1] Wu Lei, Sun Yongxing, Hu Rong. The automatic control system of all position automatic welding machine [J]. Petroleum machinery, 2006, 34 (11): 48-50.

[2] Xu Huicai, Li Jinshan. The oblique edge shears shear stress of [J]. Forging equipment and manufacturing technology, 2009, 44 (4): 29-31.

[3] Deng Bin, Xi. System of PLC control hydraulic shears [J]. Electromechanical product development and innovation, 2006, 19 (2): 63-64.

[4] Chen Manlong, Teng Deyi. Hydraulic shearing machine stress calculation [J]. Mechanical design and manufacturing,2008 (3): 54-55.

[5] Wu Hong, Jiang Shilong, Gong Xiaoyun. Current situation and development of motion controller [J]. Manufacturing technology and machine tool, 2004, (1): 24-27. 